The "Encyclopædia Britannica"-The Nile

THE volume of the Nile is made a thousand times greater than the truth in the new "Encyclopredia," vol. vii. p. 706, art. Egypt, by an error copied from the last edition. The same mistake occurs in Rawlinson's "Herodotus," vol. ii. p. 7, Note GW. ; in the Geographical Society's Fournal, vol. xix.; in Fullarton's Gazelteer, and probably elsewhere, and some fables have been founded on it.

I observed the error myself some years ago, after being perplexed by it in some rainfall estimates, and mentioned it to the late Sir Gardner Wilkinson, who intended to have it corrected; but there has been no fresh edition of the "Herodotus," and it has escaped revision in the "Encyclopædia." As it illustrates a special danger, easily overlooked, in copying French figures, it deserves perhaps a few lines in NATURE to put it right.

In English notation we mark decimals with a point, and use commas to divide periods; but the French generally use comamas to mark off decimals. The authority for the volume of the Nile is Linant's measurement, given by Clot Bey in the "Apercu general sur l'Egypte," tome i., pp. 40, 4I, and the figures are given as follows, in cubic metres of water discharged into the Mediterranean at full flood in twenty-four hours :-

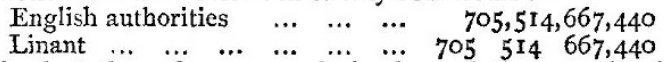

The last three figures are decimals, and the quantity is in millions, not in thousand millions.

ALBerT J. MOTT

December 14

\section{Lunar Rings}

ACCORDING to your suggestion I have followed up my experiments with lunar light on bromo-gelatine plates, and at midnight on November 28 , for the third time at full moon period I

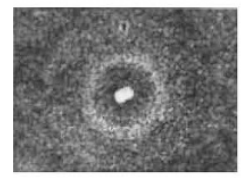

obtained on one plate three well-defined rings round the photographic image of the moon with $I$ minute, $1 \frac{1}{2}$ minute, and 2 minutes' exposure.

The I minute exposure is fainter than the above woodcut, the I $\frac{1}{2}$ minute the same in density, and the 2 minutes' exposure is denser and more defined; while six consecutive nightly observations previous to the 28 th failed to give any vinculum or indication of refraction of light.

One of the six taken on the night of November 24 with two hours' continuous exposure gave a bright clean well-defined line $2 \frac{1}{2}$ inches long, gapped here and there by passing clouds, but not the slightest indication of blurr or dispersion was shown on the brightest parts of the line.

Whether the cause which produces these rings at full moon phase only, depends upon the greater effulgence of lunar reflection at that particular time; whether it is cosmical or atmospheric in its nature, or optical or chemical, there can be no doubt that there is refraction of the lunar light; the existence of a dark space between two luminous (or more correctly speaking actinised regions) as manifested by the above annular periodical impressions is a clear indication of the dispersion of light, but how, why, or where the decomposition takes place is not so obvions.

Sunderland, December 5

GEORGE BERWICK

\section{Stag's Horns}

IT is well known to be the universal belief in the Highlands that stags eat the horns they shed, and every gillie will tell you that no one ever picked up a horn. Can any of your readers inform me what really becomes of them?

There must be abundant opportunities of observing the whole process in places like Windsor Park, where red deer are kept in a domesticated state.

G. W. H.

\section{ON A NEW COPYING PROCESS}

$A$ VERY elegant process has recently been introduced into this country for copying and multiplying letters and documents. It is known by various names, according to the etymological skill of the makers. One calls it a "hektograph," another less pardonably calls it the "centograph," while yet another, to bridge the gap between ancient Greek and modern English, styles it the "printograph." But whether it is introduced by these names, or the polygraph, the compo-lithograph, or the velocograph, the principle is the same; though the details are slightly varied in each case. A slab of gelatinous material in a shallow tin tray forms the type. The letter is written with a special ink on any kind of paper, and when dry is placed face downwards upon the jelly, and allowed to remain a minute or more. On removal it is found that the greater part of the ink has been left behind on the jelly. It is only necessary to place pieces of paper on the latter, and on their removal they are found to be perfect fac similes of the original copy. The number of copies obtainable varies with the ink, the most potent being aniline violet, such as Poirrier's. With this a hundred copies may be produced. Others, such as Bleu de Lyon, Bismarck brown, or Roseine, ${ }^{1}$ yield forty to fifty. It was with a view to determine the principles which govern this beautiful process, that I made an examination of the subject. The slab consists of gelatin and glycerine, with carbolic or salicylic acid to prevent fungoid growth, and in the "chromograph" a quantity of barium sulphate is added, which gives the slab a white, enamel-like appearance.

If a hot, strong solution of gelatin in water be prepared, ${ }^{2}$ and then a certain quantity of glycerine stirred in, the whole mass will become solid in cooling. This might at first sight appear to be a solution of gelatin in water and glycerine; but such is not the case, the gelatin being quite insoluble in glycerine. When the aqueous solution solidifies, the gelatin still retains the water, but the large quantity of glycerine being dispersed through the mass, makes the whole into what is practically a very fine gelatin sponge containing glycerine in its pores.

The moisture-loving nature of the glycerine prevents the "sponge" from getting dry, while the insolubility of the gelatin in the glycerine prevents its becoming liquid. When the copy is placed on the jelly, the glycerine comes out to meet the ink, for which it has an intense liking. All the suitable inks are freely soluble in glycerine. Some, too, contain acetic acid either in the free state or in combination with bases as in rosaniline acetate. The acetic acid exerts a solvent action on the gelatin, so that it will be found that after taking off some impressions with an acetic acid ink, as the "multiplex," the jelly will be etched wherever the ink has come into contact with it. As long as any of the ink remains on the jelly, the glycerine will come out of the pores to keep it moist, but when the whole of the ink has been removed the flow of glycerine ceases, and the parts become quite dry. If the ink is not entirely removed by taking a sufficient number of impressions, and the jelly left, after a lapse of twentyfour hours the remaining ink will be absorbed by the jelly. It is necessary, therefore, that the copies should be taken off as soon as possible, so as to avoid the defect caused by the spreading of the ink.

Most of the makers suggest, that directly the slab is done with, the type should be washed off. The hektograph and most others require that the water should be warm, but the finely divided barium sulphate in the chromograph, renders the surface less tenacious, and the impression may be removed with cold water.

Where practicable, it is better in all cases to leave the slab for twenty-four hours, when the old impression will be quite absorbed, and not interfere with a new one.

This gelatin copying process has been received with so

I A very pctent and easily prepared ink which will yield a hundred copies, may be made by dissolving rosanilne in a cold-saturated solution of oxalic acid. It must be allowed to dry spontaneously.

$4 \mathrm{cz}$. gelatin dissolved in $6 \mathrm{cz}$. water, and $20 \mathrm{oz}$. glycerine, sp. gr. $\mathrm{r}_{2} 6$, previously warmed, stirred in. Any air bubbles in the gelatin are rem oved before the addition of the glycerine. A cheaper compound which answers equally well, but is rather darker, ccnsists of Scotch glue $6 \mathrm{oz}$, water $8 \mathrm{oz}$. glycerine 2002 . These quantities make a slab to $\times 13 \times 1$ 